\title{
LA PRAMMATICA DEGLI ÄGGETTIVI DIMOSTRATIVI RUMENI
}

0.1. Il rumeno, come il francese ed i dialetti ladini, dispone di un sistema binario che, per quanto riguarda la distanza, prende come punto di riferimento il locutore, distinguendo fra la sua "lontananza" e la sua "vicinanza"."

L'italiano e le altre lingue neolatine hanno invece un sistema ternario che prende come punto di riferimento sia il locutore sia l'allocutore: si distingue tra "vicino al parlante", "vicino all'allocutore", "Iontano dal locutore e dall'allocutore" (questo, codesto, quello).

In realtà però questa differenziazione si fa soltanto ancora nella lingua letteraria di stile elevato, sia nell'italiano sia in altre lingue neolatine.

Benché limitato al sistema binario l'inventario dei dimostrativi rumeni ha quattro forme, grazie al fatto che i due lessemi di base acest e acel hanno delle forme parallele più brevi (ăst e $\underline{a} l)$. E' vero però che la distribuzione stilistica di queste forme non è la stessa.

Gli aggettivi dimostrativi rumeni differiscono inoltre, per quanto concerne la forma, secondo la loro posizione, cioè se si trovano prima o dopo la parola determinata, nel senso che se è postdeterminante l'aggettivo prende ancora una desinenza in - $a$ (diventando in tal modo formalmente identico al pronome dimostrativo): acesta ed acela.

Astraendo dalle locuzioni oggigiorno arcaicizzanti del tipo ăst + nome e $a \underline{a} l+$ nome (per esempio ăst om e $\mathrm{e} l \mathrm{om}$ ), che attualmente si trovano solo in frasi di formula fissa come de astă datăg astă vară, astă noapte ecc., "questa volta", "quest'estate", "questa sera" ecc., lo schema degli aggettivi deittici è il seguente:

1 Per più dettagli e bibliografîa cfr. Réflexions sur l'emploi des adjectifs démonstratifs roumains, dans Akten der Theodor Gartner-Tagung, edd. G. Plangg e M. Iliescu, Innsbruck, 1987 (Romanica Aenipontana XIV), p. 305-315 

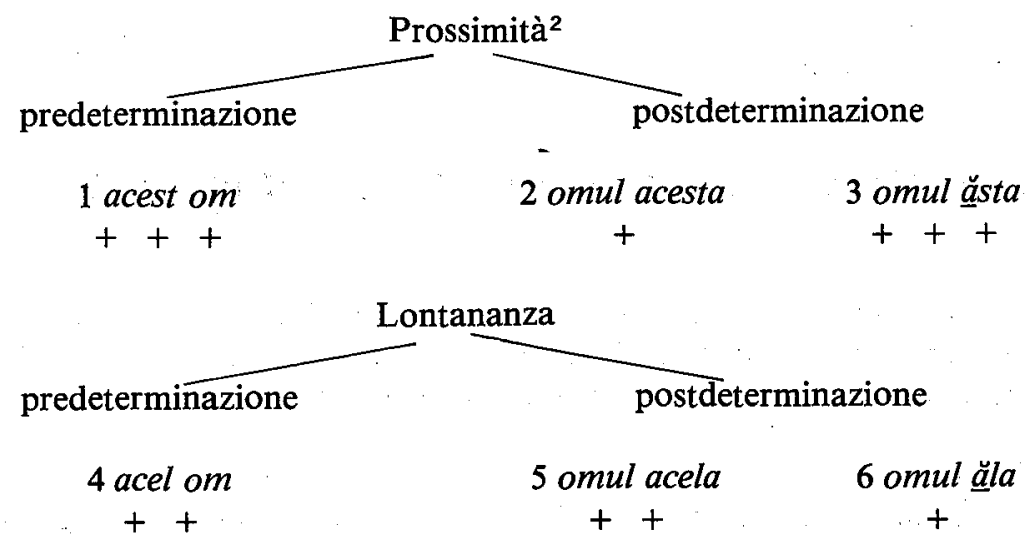

Per quanto concerne la distribuzione secondo frequenza e stile, le ricerche recenti hanno mostrato che

a) le forme 1 e 3 sono usate nella stessa misura sia per la lingua parlata correntemente sia per la lingua scritta. La lingua elevata sceglie tra le forme 1 e 2 . La forma 1 è in questo caso molto più frequente che la forma 2 .

b) La lingua elevata e quella corrente usano in ugual misura le forme 4 e 5 .

c) La forma 6 è molto meno frequente che non le forme $4 \mathrm{e} 5$, è inoltre anche meno usata della forma 3, sua corrispondente della serie "prossimità". Questa forma è caratteristica della lingua popolare corrente e di quella familiare orale, incominciando solo adesso ad entrare timidamente nella lingua corrente scritta.

Qui di seguito ci proponiamo di analizzare i valori pragmatici degli aggettivi dimostrativi rumeni. Per semplificare quanto esponiamo adottiamo la terminologia di A. Lombard ${ }^{3}$, cioè: serie -st- per le forme acest, acesta e ăst, serie -l- per le forme acel, acela e $\underline{a} l$.

1.0. Per poter trarre delle conclusioni sul funzionamento dei dimostrativi nella performanza pratica dell'uso, abbiamo sottoposto ad un esame testuale e pragmatico un "corpus" proveniente dallo spoglio di 773 pagine di letteratura contemporanea rumena. Il testo più antico risale al 1965 , quello più recente al 1987. Uno dei testi è la traduzione di un romanzo di Simenon. I brani prescelti offrono una gamma stilistica molto ampia ${ }^{4}$.

1.1. Il valore semantico dei dimostrativi è ben lontano dal limitarsi ad una semplice indicazione della dimensione "distanza", come si potrebbe facilmente credere in base alle descrizioni che si trovano solitamente nelle grammatiche, e questo non soltanto in quelle rumene.

2 Le crocette mostrano la frequenza relativa.

3 Le roumain. Une présentation, Paris, Klincksieck, 1974, 165.

Cf. supra. 
Il valore molto generale dei dimostrativi è quello dell'identificazione. Gli esempi del "corpus" permettono di distinguere un primo gruppo in base alla ripartizione /noto/ e /non noto/. Nel primo caso si tratta di un'identificazione di richiamo (1), nel secondo (2) di un'identificazione di presentazione.

(1) ... Cum spune un mare scriitor, n'ai auzit de el, cum n-ai auzit de mulţi alţii: de A. Huxley cu atît mai puţin: are batrînul Vercenca un volum de eseuri ale acestui Huxley (Z. 53).

"Come dice un grande scrittore, tu non hai mai sentito parlare di lui, come tu non hai mai sentito parlare di molti altri: di A. Huxley ancora meno: il vecchio Vercenca ha un volume di saggi di questo Huxley“.

(2) Nu puteau urma convoiul pentru a fi martori la acel eveniment rarisim - oprirea unui accelerat din ordinul șefului lor. (E. L. 10)

"Non potevano seguire il convoglio per essere testimoni di questo avvenimento rarissimo - l'arresto d'un treno espresso su ordine del loro capo“.

1.1.1. Il richiamo per mezzo dell'aggettivo dimostrativo si può fare tramite la ripetizione di una nozione verbalizzata precedentemente in un qualsiasi discorso (3) oppure tramite la ripresa di una nozione non verbalizzata prima, ma che si presuppone nota all'interlocutore oppure all'allocutore (4).

(3) Eu mă refeream la un balon de defilare, nu la baloanele alea din $1910 \ldots$ Toate balonaele alea din 1910 au luat foc. (E. L. 79)

"Pensavo ad un pallone da sfilata (partecipando ad una manifestazione) e non ai palloni del 1910 ... Tutti quei palloni del 1910 hanno preso fuoco".

(4) Am mers împreuna la ai mei, știi cum este, în familie, atmosfera aceea de familie. (B. 13)

"Siamo andati insieme dai miei, sai com'è, l'atmosfera di famiglia“.

A volte il locutore riprende una nozione conosciuta solo da lui: questo è il caso di narrazioni dove l'autore vuol attirare il lettore nella sua intimità. L'esempio che segue è costituito dalla prima frase di un romanzo. Una verbalizzazione anteriore è stata dunque impossibile.

(5) Mă urcam în autobuzul acela străvechi şi ... mă rugam să ajungem în mica piaţă a gării.

"Sono salita su quel vecchio autobus e pregavo il cielo di arrivare alla piazzetta della stazione". 
1.1.1.1 Il richiamo della nozione conosciuta tramite la verbalizzazione può essere fatta anche con la ripetizione della stessa parola (6), con un sinonimo (7), con un iperonimo (8) oppure con una parafrasi (9).

(6) Deocamdată adun material. Clasez. Mă grăbesc însă. Ca şi cum aş fi presat de un contract. De necrezut, ca şi cum aş fi încheiat acest contract chiar cu Antipa.

"Per il momento raccolgo il materiale. Classifico. Mi affretto. Come se fossi incalzato da un contratto. Incredibile, come se avessi stipulato questo contratto con Atipa stesso“.

(7) Deci un singur vinovat posibil: $X$. Adică un individ pe care nu l-am întîlnit înca ... Pe acest om nu-l cunoaştem. (S. 104)

"Dunque un solo colpevole possibile: $\mathrm{X}$. Un individuo che non abbiamo ancora incontrato ... Quest'uomo non lo conosciamo“.

Nel caso di ripresa con un iperonimo si tratta di solito del genere prossimo alla nozione verbalizzata:

(8) A adormit în adîncul fotoliului Baroni. In casa aşa i se spunea acestui obiect: fotoliul Baroni. (G. B. 21)

'Si è addormentato sprofondato nella poltrona Baroni. In casa quest' oggetto si chiama così: la poltrona Baroni“.

Il caso più frequente è quello delle parafrasi, di solito esplicative:

(9) [Nu reuşea] sa treacă de la comprehensiunea "existenței“ ca existenţă, la comprehensiunea de tipul minus-cunoaşterii, acea revelare a ascunsului. (Z. 67)

"Non riusciva a passare dalla compresione dell'esistenza come esistenza, alla comprensione di tipo meno-conoscenza, questa rivelazione del nascosto".

Le spiegazione può anche essere enfatica, come nell'esempio seguente:

(10) Cît sînge rău mi-au făcut ei, oamenii aceia!

"Quanti dispiaceri mi hanno dato [loro] questi uomini!"

Nell'esempio (10) la verbalizzazione è realizzata da un pronome ripreso da un sostantivo. Il cambiamento della categoria grammaticale non è un fatto isolato: di solito accompagna una generalizzazione, (cfr. infra): 
(11) Căsca ochii, îşi umfla obrajii, scotea limba ... şi la toate aceste mişcări bărbatul în haine dungate ... răspundea cu altele asemănătoare. (E. L. 78)

"Spalancava gli occhi,gonfiava le gote, tirava fuori la lingua ... e a tutti questi movimenti l'uomo in abito a righe rispondeva con altri movimenti simili“.

I verbi căsca, umfla, scotea sono qui ripresi dall'astratto verbale mişcare.

Le parafrasi metonimiche (12) e metaforiche (13) hanno evidentemente anche un carattere esplicativo:

(12) Oftează adînc şi respirația aceasta chemată din fundul plămînilor ... vrea să însemne nu numai un regret ... (O. I. 49)

"Egli sospira profondamente e questa respirazione fatta uscire dal fondo dei polmoni ... non vuole esprimere soltanto un rincrescimento“.

La "respirazione" è una parte del "sospiro": si tratta dunque di una sineddoche. La prima nozione viene espressa con un verbo, la seconda invece con un sostantivo.

(13) - Intîi să mîncăm ceva.

- Mănîncă, dacă vrei, eu nu practic sportul ăsta dimineaţa. (Z. 127)

"- Anzitutto mangiamo qualcosa"

"- Mangia, se vuoi, io non pratico questo sport la mattina".

Con una metafora "mangiare" ̀̀ considerato uno "sport". Abbiamo dunque un nuovo cambiamento della categoria grammaticale, senza importanza per la nozione lessicale: sa mîncăm, mănînca: verbi; sport: sostantivo. L'esempio (14) è una metafora usata in un linguaggio speciale, cioè quello della medicina, una metafora dove non troviamo un cambiamento grammaticale.

(14) E o eroare ... să tratezi cu uşurinţă unele simptome şi să le treci ... pe seama tulburărilor neuro-vegetative, acest sac fără fund al medicinei actuale. (O. I. 89) ' $E$ ' un errore ... trattare alla leggera certi sintomi conseguenze di disturbi neurovegetativi, questo sacco senza fondo della medicina attuale“.

Nell'esempio che segue la ripresa si riferisce ad una forma grammaticale che esprime una relazione sociolinguistica:

(15) - Nu-mi povestiți, că nu mă interesează!...

— N'o să sfirşseşti odată cu acest plural?! (E. L. 99)

“- Non raccontatemelo, perché ciò non m'interessa!...

“- Non vuoi finirla una volta per tutte con questo plurale?! 
La parola plural riprende la forma plurale della persona del verbo povest $i$ (povestiti) che si usa quando si vuole dare del lei a qualcuno.

Molto spesso il richiamo non riguarda soltanto un'unica parola, infatti si può trattare invece di due (16) o più parole o sintagmi (11) (17) che vengono ripresi da un lessema più generale, il cui campo logico è più vasto.

(16) Este o idee greşită ca pe acoperiş merg să contemple stelele numai pisicile şi motanii, aceste fïnţe odioase, proaste şi viclene. (G. B. 43)

'E' un'idea falsa che sul tetto vadano a contemplare le stelle soltanto le gatte e i gatti, questi esseri odiosi, stupidi e furbi“"

(17) Sîntem împreună de şapte ani şi ne cunoaştem de zece şi ... în tot răstimpul ăsta spui că eu n-am făcut altceva decît să te mint.

"Siamo insieme da sette anni e ci conosciamo da dieci anni e ... tu dici in tutto questo tempo io non ho fatto altro che mentirti“.

Răstimp riprende evidentemente şapte ani e zece ani.

A volte si tratta di riprendere tutto un "testo", implicito oppure esplicito, per mezzo di una parola generalizzante (18), (19):

(18) S-ar părea, la o prima vedere, că un drum modernizat nu înseamnă decît un drum modernizat şi atîta tot, dar nu-i aşa! Operația asta ... a condus la schimbarea comunelor, la púnerea în valoare a zonelor turistice din județ. (O. I. 97)

"Sembrava, a prima vista, che una strada modernizzata non rappresentasse altro che una strada modernizzata e basta, ma non è così! Quest'operazione ha avuto il risultato di trasformare i comuni e di valorizzare le zone turistiche del distretto".

Il sintagma nominale drum modernizat è ripreso dal sostantivo più generico operatie che designa tutti i lavori necessari per giungere ad una strada modernizzata.

(19) La un moment dat Miron s-a apropiat de mine şi mi-a spus cã aceea era ultima lui vacanţă care urma să dureze cîteva zile doar, înainte de a-şi lua diploma de inginer. Urmărind plonjoanele lui Dan, $\mathrm{n}$-am dat atenţie acelor cuvinte. ( $\mathrm{E}$. L. 59)

"Ad un dato momento Miron mi si è avvicinato e m'ha detto che erano quelle le ultime vacanze che duravano solo alcuni giorni, prima di ottenere la sua laurea d'ingegnere. Guardando Dan mentre si tuffava non ho dato importanza a queste parole". 
Assai sovente la ripresa tramite generalizzazione è realizzata da dei sintagmi lessicalizzati come tali; a giudicare dal nostro corpus, i più frequenti di questi sintagmi sono i seguenti: lucrul acesta/ästa // treaba asta // chestia asta, fenomenul acesta, problema aceasta /ăsta; în cazul ăsta/acesta; în felul ăsta/acesta; $\mathrm{N}+$ de acest fel; acest fel de a + verbo all'infinito; verbo dicendi + aceste vorbe / aceste cuvinte; verbo + in acest sens, din acest punct de vedere / din punctul acesta de vedere; în această privintắ; de acestă dată / de data aceasta / de data asta; anul acesta / asta, luna aceasta / asta. "Ciò / questo fattto // questo caso //; questo fenomeno, questo problema; in questo caso; di questa maniera; $\mathrm{N}+$ di questa specie; questo modo di + verbo all'infinito; verbo dicendi + queste parole; verbo + in questo senso, da questo punto di vista; questa volta; quest'anno; questo mese“.

$\mathrm{Ci}$ accontentiamo di quattro esempi che illustrano le differenze stilistiche, (20) stile standard, (21) stile corrente, (22) (23) stile familiare.

(20) ... ceea ce îi oferea şansa de a înlocui vizitele la doctori cu îndeletniciri mai placute ... - dar lucrul acesta nu-l spunea. (E. L. 82)

“... ciò che gli dava la possibilità di sostituire le visite mediche con delle occupazioni più piacevoli - ma questo non lo diceva.

(21) Trebuia să fac lucrul ăsta de la început. (M. 14)

“Avrò da fare ciò / questa cosa fin dal principio“.

(22) Treaba asta 1-a cam ruşinat ... (O. I. 83)

“Questa faccenda l'ha reso un po' vergognoso“'...

(23) - O iubeşti pe Tania, sau nu?

- Lasă chestia asta! (Z. 226)

“- Tu ami Tania, oppure non l'ami?

“-Lascia stare!" /"Basta!"/

1.1.1.1.2 La ripresa di una verbalizzazione può far parte della dimensione "prossimità" o della dimensione "Iontananza". In rumeno la prossimità viene generalmente espressa con l'aiuto del tipo -st-, la lontananza, invece, con la serie -l-. Le due dimensioni possono essere considerate in relazione 1) al testo o 2) al parlante.

1) Nel primo caso si tratta della distanza fra la verbalizzazione e la ripresa della verbalizzazione. Ma le distanze proprie alla prossimità ed alla lontananza sono a loro volta delle dimensioni variabili. 
L'esempio (24) è un'anafora esplicativa metaforica: la verbalizzazione e la sua ripresa sono l'una accanto all'altra. La prossimità è evidente:

(24) Nepreţuită e uitarea, darul ăsta pe care ni 1-a făcut natura (E. L. 46)

"Inestimabile, l'oblio, questo dono che ci ha fatto la natura".

L'esempio (25) è un'anafora con ripresa della parola di verbalizzazione. La distanza fra la parola e la ripresa è già più grande, benché ancor sempre nell'ambito linguistico della prossimità.

(25) Peste tot există planuri de sistematizare, ce proiectează blocuri cu încălzire centrală si clădiri administrative cu multe etaje. E foarte bine, e normal ca omul să trăiască mai comod şi mai liniştit. Dar aceasta sistematizare trebuie să ţină seama de locul respectiv, de tradiţie, de firea şi de trecutul oamenilor. (O. I. 34)

"Dappertutto ci sono dei piani di sistematizzazione, si progettano case con riscaldamento centrale ed edifici amministrativi a molti piani. E' giustissimo, è normale che gli uomini vivano in modo più confortevole e più tranquillo. Ma questa sistematizzazione deve tener conto del luogo dato, della tradizione, del carattere e del passato delle persone.“

Il testo che segue (26) è specifico per la dimensione "lontananza":

(26) - Lia, la telefon, mi se adresa ea. (E. L. 44)

- Dece ai stat atîta Lia? Telefonul ala a fost doar un pretext? (E. L. 51)

- Lia, al telefono mi ha detto.

- Perché ti sei assentata tanto tempo, Lia? Quella telefonata è stata solo un pretesto?"

2.1.2.2. Se la prossimità e la lontananza sono relative al parlante si tratta soprattutto a) del parametro oggettivo "tempo".

a) (27) Aflu ca sînteţi ... director din 1969. Cum de atunci au trecut, iată, 16 ani, ard de nerăbdare să aflu ce-aţi făcut pînă în acel moment. (O. I. 94)

"Sento che lei è ... direttore dal 1969. Dato che da allora son passati ben sedici anni, muoio dalla curiosità di sapere che cosa ha fatto fino a quel momento".

(28) Perfecţiunea ..., zicea, nu există decît la indivizi ideali, adică la cei care vrem noi sa devenim ... Slavă Domnului, mai e pînă atunci, n-apucăm noi timpurile alea. (E. L. 50) 
"La perfezione ..., diceva, non esiste che negli individui ideali, cioè in quelle persone che vorremmo diventare ... Grazie a Dio è ancora lontano, noi non vedremo quei tempi“.

Negli esempi (27) (28) la scelta della serie -l- è dovuta al tempo passato della narrazione. La distanza fra verbalizzazione e ripresa è minimale. In questo caso non è possibile sostituire la serie -st- alla serie -l-.

2) a) Negli esempi seguenti la scelta dell'aggettivo dimostrativo si spiega con il fattore "soggettività personale" del parlante.

(29) ... domnu Puiu, căre-mi apucă din ce în ce mai des mîinile în ale sale ... Aș da tot ce am ca să pot smulge amintirea omului acelui scîrbos din memoria mea, s'o azvîrl la cîni, să nu mă mai gîndesc niciodată la el. (E. L. 24)

“... il signor Puiu, che prende sempre più frequentemente le mie mani nelle sue ... Darei tutto quello che possiedo per poter strappare dalla mia memoria il ricordo di quell' uomo disgustoso, gettandolo ai cani, per non pensare mai più a lui“.

Ci si attenderebbe qui la serie -st-, a causa della prossimità testuale e temporale (il presente nella prima proposizione); il narratore ha scelto invece acela, perché soggettivamente vorrebbe la lontananza della persona indesiderata. La sostituzione con la serie -l- è possibile.

Inversamente acea potrebbe essere sostituito da aceasta nell'esempio (30).

(30) Dan plecase la Constanţa cu o zi înainte ... aşa că eram singură ... şi atît de deprimată. In acea stare sufletească ... m-am trezit cu Miron alături.

“Dan era partito per Constanza il giorno precedente ... siccome ero sola ... e tanto depressa. In quello stato d'animo ... mi sono resa conto, tutto a un tratto, che Miron era vicino a me“.

Benché l'avvenimento sia al passato, l'inalienabilità dei sentimenti della persona che racconta permetterebbe la sostituzione di acea con aceasta .

b) L'esempio (29) ci presenta il passaggio ad un altro fattore che influenza la scelta di acel(a): la connotazione peggiorativa. Nella maggior parte dei casi il dimostrativo accompagna un determinato peggiorativo (31), oppure il determinato è accompagnato da un altro determinante peggiorativo (32).

(31) Ce i-aş mai îndoi ăstuia mutra aia de domnişoară! (Z. 143)

“Come vorrei rompere a quel tipo là quel suo musetto da signorina!“ 
La traduzione alla lettera sarebbe "quella figura". Mutra è il sinonimo peggiorativo di față "faccia".

(32) Il prinsesem într-o poziţie ... mai delicată ... In poziţia aia neruşinată, s-a întors spre mine şi mi-a zis. (E. L. 50)

“L'avevo sorpreso in una posizione un po' delicata ... In quella posizione sfacciata si è voltato verso di me e m'ha detto“.

(33) Un doctor a numit asta voluptatea băii ... /cinque righe/ Cum spunea ... doctoraşul ăla ... (E. L. 70)

"Un medico l'ha definito la voluttà del bagno ... Come diceva quel dottoruncolo là ..."

Il diminutivo doctoraşul è un peggiorativo. Il narratore pensa che si tratti di un cattivo medico, al quale non si deve credere.

In tutti e tre questi esempi sarebbe possibile la sostituzione con la serie st-. La scelta è dovuta in primo luogo alla connotazione peggiorativa. Una forma particolare per esprimere la connotazione spregiativa è costituita da un sintagma nominale, composto di un nome seguito da un aggettivo dimostrativo (soprattutto della serie -1-), succeduto da un nome introdotto con la preposizione de:

(34) La ce te puteai aştepta de la rabla aia de maşină. (E. L. 11)

"Questo era ciò che ci si poteva aspettare da quella vettura sgangherata".

Il termine peggiorativo rabla avrebbe potuto essere seguito da asta, ma la scelta di aia rafforza la connotazione spregiativa.

(35) O sticlă de whisky: "asta e de la capitaliştii ăia de franţuji“. (Z. 105)

"Una bottiglia di whisky: "viene da quegli capitalisti di francesi“.

c) Un altro elemento che influenza la scelta della serie -1- è il sema /irrealtà/, /-concreto/. Ecco qualche esempio:

(36) - "După ce.îmi voi primi toate proprietăţile înapoi, o să te duc să vezi“ ... Şi nu se îndoia că va apuca ziua aceea". (Z. 88)

- "Dopo aver riottenuto tutte le mie proprietà ti porterò a vederle" ... E non dubitava affatto che quel giorno sarebbe venuto". 
Nell'esempio che segue l'improbabilità della presupposizione espressa è molto grande. La persona che parla è anziana e l'evento sperato è connesso ad un cambiamento quasi impossibile.

(37) Aceleaşi amestec de euforie şi de luciditate oarecum desprinzîndu-l de timp ... îi reactiva din dedesubturile memoriei, probabil în continuarea visului, tot soiul de detalii despre bunicul lui, mort înainte ca el sa fi împlinit cinci ani. Işi săpunea barba şi în oglindă prindeau contur acele detalii, mai mult din spusele celoralți decît din sursă directă. (Z. 128)

"La stessa mescolanza di euforia e di lucidità che in un certo modo lo staccavano dal tempo ... riattivava nelle profondità della memoria, probabilmente continuando il sogno, ogni genere di particolari su suo nonno, morto prima che egli avesse compiuto $i$ cinque anni. S'insaponava la barba e nello specchio questi dettagli acquistavano dei contorni, ma erano piuttosto quelli che gli altri gli avevano raccontato e non quelli di fonte diretta“.

Considerando la prossimità testuale ci si sarebbe aspettati invece aceste detalii. L'elemento /irrealtà/, molto pronunciato in questo testo, spiega la scelta fatta.

2.1.3. Ci sono però dei casi dove è difficile dire se si ha a che fare con la ripresa della verbalizzazione di una nozione, oppure con la ripresa di un elemento che si presuppone nato, a causa di tutto il testo precedente. Ciò succede anzitutto quando nella narrazione abbiamo la tematizzazione di una nozione.

(38) Dar omul ... bagă de seamă în apropiere un prag cu două trepte, se adăposteşte acolo ... Omul se prăbuşeşte la pamînt. (S. 12)

- Şi eu aş fi putut, la fel cu el să mă adăpostesc pe acel prag. (S. 24)

"E l'uomo ... scorge una soglia con due gradini, si mette là al riparo ... Si corica sul suolo".

- "Anch'io, come lui, avrei potuto ripararmi su quella soglia“.

La "soglia" è un elemento tematico del romanzo di Simenon, perché la vittima era stata ammazzata proprio là.

(39) - Dar cîinele ăsta, ce-i cu el? (S. 13)

- "E questo/quel cane"?

La verbalizzazione più vicina di cîne si trova ad una distanza testuale di cinquantun righe. Questo testo interposto è inoltre scisso da un sottocapitolo! La ripresa non è solo possibile, ma è la stessa, cioè con asta.

Nel romanzo il "cane" costituisce un elemento chiave, anzi intitola il romanzo stesso. Si può dunque attualizzarlo in vari modi. 
Facciamo ancora un esempio di ripresa per mezzo della generalizzazione di tutto il testo precedente, sempre con i pronomi della serie -st- in funzione di attualizzatori.

(40) - De fapt toată istoria asta e un fel de nimica toată. S. 65)

"Infatti, tutta questa storia non è per niente importante“.

2.2. Questi ultimi esempi constituiscono un adeguato passaggio al secondo tipo di "ripresa", cioè quella del presupposto noto e non verbalizzato precedentemente.

La presupposizione della conoscenza pud riferirsi al parlante (2.2.1.) e all'allocutore oppure (2.2.2.) soltanto al parlante. Quest'ultimo caso è realizzabile solo in una narrazione nella quale il parlante (cioè il narratore) vuole attirare il suo lettore (interlocutore, allocutore) nella propria sfera di conoscenza e di familiarità.

La maggior parte degli esempi riguardanti l'attualizzazione di un presupposto noto usa il dimostrativo acela. Ciò si spiega probabilmente con il fatto che la presupposizione stessa implica il carattere /- concreto/, molto vicino a quello di /irrealtà/, di cui abbiamo parlato in precedenza.

2.2.1. (41) Hai, omule, să vindem perii aceia. (Z. 147)

"Andiamo, vendiamo questi peri“.

Si presuppone che il parlante e l'allocutore conoscono le perii, ma nel testo precedente non se n'è parlato affatto.

2.2.2. Il secondo caso è illustrato benissimo dall'esempio (5), con il quale incomincia tutto un libro, per cui è impossibile la ripresa mediante verbalizzazione.

(5) Mă urcam în autobuzul acela străvechi. (E. L. 5)

"Salivo su quel vecchio autobus".

Il dimostrativo e l'imperfetto sono due elementi stilistici che servono ad introdurre il lettore nell'azione il più rapidamente possibile.

Nell'esempio seguente acel è necessario a causa di tre fattori: la presupposizione, il passato e l'irrealtà.

(42) Locurile bătute şi răzbătute în copilărie şi-au pierdut vraja de altădată; nu se mai repetă acele întîmplări misterioase, duhurile nu mai şicanează oamenii. (Z. 110) 
"I luoghi percorsi e ripercorsi durante l'infanzia hanno perso l'incanto delle altre volte; quegli avvenimenti misteriosi non si ripetono più, i fantasmi non tormentano più le persone“. acele.

In questo testo l'irreale è espresso da vraja, misterioase, duhuri e dalla scelta di

2.2.3. Troviamo tuttavia anche degli esempi dove il presupposto noto è ripreso dalla serie -st-. Nei casi esaminati nel nostro corpus si tratta di catafore ellittiche che possono coincidere con un'attualizzazione.

(43) [Sînt] utilă în această slujbă. (E. L. 62). E’ sottinteso: pe care o am.

[Sono] utile in questo servizio /che ho/.

L'esempio (44) è lessicalizzato nel senso che lumea aceasta si oppone a lumea aceea /cealaltä. Lumea aceasta ha il significato di "lumea aceasta în care trăim".

(44) Despărţirea lui de această lume. (Z. 75)

"Il suo distacco da questo mondo".

3.0. L'identificazione di ciò che non è noto, come abbiamo già detto, può verificarsi mediante dimostrazione (la deissi propriamente detta $=$ in presenza) oppure mediante caratterizzazione ( $=$ in assenza).

3.1. L'identificazione dimostrativa può essere locale o temporale e può implicare la lontananza o la prossimità.

Come nel caso del richiamo, la prossimità si esprime con l'aiuto della serie -st-, mentre invece la lontananza usa la serie -l-. L'aggettivo di prossimità locale può essere enfatizzato da de aici "(di) qui"; quello di prossimità temporale da de acum “(da) adesso“. L'aggettivo di lontananza locale potrebbe essere accompagnato da de acolo "di là", quello di lontananza temporale da de atunci "da allora".

3.1.1. Nella serie della prossimità le forme brevi àsta/asta sono preponderanti.

\subsubsection{Prossimità locale:}

(45)

— Nu mai îndrăznesc să dorm. Fereastra asta, uitaţi-vă la ea... (S. 121)

“- Non oso piu dormire ... Questa finestra, guardatela"!

(46) - Iţi iei şoşonii ăştia mari si groşi, pensionarii ăştia?

“- Prendi queste galosce grandi e grosse, queste pensionate?“ 
(47) - Trebuie să fie de pe-aci. Poate chiar de pe scara asta. (M. 19)

“- Dev'essere da queste parti. Anzi, forse abita in questa scala“.

3.2.1.2. Prossimità temporale:

(48) - Diapazonul ăsta ... mi l-a cumpărat băiatul luna asta. (O. I. 14)

"- Questo diapason me l'ha acquistato mio figlio questo mese".

In alcuni testi la prossimità temporale può essere hic et nunc:

(49) - Of, cu toată căldura asta, Bucureştiul mi s-a părut încîntător. (E. L. 91)

“- Uff! Con tutto questo gran caldo Bucarest m'è parsa tuttavia una città meravigliosa“.

"Con tutto questo gran caldo" può essere completato da: di qui, adesso. La grande maggioranza degli esempi deittici di prossimità del nostro "corpus" provengono da discorso diretto.

3.1.2.1. I deittici della lontananza esprimono una gamma più ampia di sensi rispetto a quelli della prossimità. Gli esempi del discorso diretto sono meno frequenti. Nel nostro corpus ne abbiamo trovato uno solo:

(50) - Priviţi visavi: clădirea aceea noua, căreia lumea îi zice motel, e un hotel (O. I.)

"Guardi di fronte: quel nuovo edificio là, che la gente chiama motel, è un albergo".

Il tempo passato di una narrazione richiede i dimostrativi della serie -l-, perfino quando si tratta di prossimità locale:

(51) Dacă batrîna mi-ar fi răspuns că nu-1 cunoaşte, mi-aş fi cerut scuze şi aş părăsit îndată curtea aceea. (E. L. 94)

"Se la vecchietta mi avesse risposto che non lo conosceva, avrei fatto le mie scuse e me ne sarei andato da quel cortile“.

Il cortile si trova vicino al narratore, ma nel passato: l'ultimo elemento predomina; la scelta cade sulla serie -l-.

Le cose sono più semplici nell'ambito della lontananza temporale:

(52) Noaptea aceea a fost într-adevăr noaptea paharelor. (S. 58) 
“Quella notte fu veramente la notte dei bicchieri e dei piatti“

I tre esempi del corpus che usano l'aggettivo ăla/aia esprimono solo una sfumatura stilistica popolare o molto familiare. Non c'e affatto traccia di connotazione peggiorativa.

(53) Şi în momentul ăla mi s-a făcut frică. (S. 132)

"E in quel momento ho avuto fifa".

L'esempio (54) ha anche un senso apprezzátivo.

(54) Poate că într-o zi, cîndva, băiatul lui va îmbrăţişa aceeaşi meserie. Costache ăia, o să zică lumea, păi sînt forestieri din tată-n fiu! (O. I. 45)

"Forse un giorno suo figlio sceglierà lo stesso mestiere. Questi C., dirà la gente, sono guardaboschi di padre in figlio“.

3.2. Il secondo tipo d'identificazione mediante presentazione è quello "in absentia“, che si realizza tramite la caratterizzazione.

Per questa funzione in rumeno si usa la serie -1-, spiegabile con il fatto che si tratta di un "oggetto" in linea di massima non presente. La maggior parte degli esempi del corpus presenta l'aggettivo acel(a).

La caratterizzazione avviene soprattutto per mezzo di una proposizione relativa determinativa.

(55) Intre conte şi Bratu se insinuase acea tainică simetrie a comunicării dintre senectute si copilărie, datorită căreia batrînii îşi îndrăgesc nepoţii. (Z. 86)

"Fra il conte e Bratu s'era insinuata quella misteriosa simmetria di comunicazione tra vecchiaia ed infanzia, grazie alla quale gli anziani amano i loro nipoti“.

(56) In volgă resimţea acel sentiment de siguranţa şi putere, ce-l înălţase de-atîtea ori în ochii lor. (Z. 81).

"Nella volga aveva provato quel senso di sicurezza e di forza che l'aveva tante volte innalzato ai loro occhi“.

La frase relativa può essere sottintesa:

(57) Indiferent ce impresie le făcuse mutra lui angelică şi acea condescendenţă implicită sau explicită, un fel de "A, păi tu nu ştii cum a fost“. (Z. 112) 
"Indifferentemente dall'impressione che aveva fatto la sua figura angelica e quella condiscendenza implicita o esplicita, una specie di "Tu non sai come sono avvenute le cose“.

I due esempi del nostro corpus che comportano il pronome breve $\underline{a} l a$ non sono connotati. I testi provengono dallo stesso autore (Modorcea) e sono scritti in una lingua più familiare. Ecco uno di questi esempi:

(58) Nu găsise metalul ăla zimţat ca o pilă, cu care se taie capul fiolei. (M. 13)

"Non aveva trovato quel metallo dentellato come una seghetta, con il quale si taglia l'estremità della fiala“.

In tutti i casi del nostro corpus in cui la relativa determinativa si trova dopo dei dimostrativi della serie -st-, si tratta o di un'anafora (di generalizzazione (59)) o di una nozione presupposta come nota che si provvede di un'ulteriore spiegazione (60).

(59) A trebuit să plece, omul, cu treburi ... la Paris. Mulţi din oamenii ăştia, care fac atîta caz că sînt bucureşteni, suferă de obsesia Franţei. (E. L. 92)

“E' dovuto partire per degli affari ... a Parigi. Molte di queste persone che sono così fiere di essere abitanti di Bucarest, soffrono dell'ossessione della Francia“.

(60) Ce frumoasă e vîrsta asta, cînd poţi fi deopotriva poet si portar de fotbal! (E. L. 59)

"Quant'è bella quest'epoca, in cui si può essere nello stesso tempo poeta e portiere in una squadra di calcio!"

Vîrsta non ha antecedenti nel testo.

Una spiegazione cataforica con un dimostrativo della serie -1- può anche andare di pari passo con una nozione che si presuppone nota, come nell'esempio seguente. Si tratta di una lettera mediante la quale chi scrive vuole convincere il destinatario a non rimanere più nella località dove abita, evidentemente conosciuta dai due scriventi.

(61) “Ai face mai bine să vii aici decît să stai în groapa aceea murdară unde plouă tot timpul." (S. 115)

"Farai meglio a venire qui, piuttosto che restare nel tuo sporco buco, dove piove sempre“. 


\subsection{Ricapitoliamo:}

L'analisi testuale delle funzioni degli aggettivi dimostrativi, che forse possiamo anche considerare degli universali linguistici neolatini, se non addirittura indoeuropei, permette di distinguere fra parecchi gruppi semantico-pragmatici.

I dimostrativi servono a prima vista ad identificare delle nozioni note e/o non note. Quelle note possono esserlo per verbalizzazione precedente oppure possono essere solo presupposte come note. Nel primo caso la verbalizzazione precedente si può trovare ad una distanza oggettiva o soggettiva dal parlante. Se la distanza è oggettiva si tratta sia della distanza nel testo, dunque una distanza evidentemente locale, sia della distanza fra il tempo assoluto e quello relativo; in altre parole fra l'avvenimento dov'è implicita la nozione e la narrazione del parlante.

La realizzazione linguistica della ripresa di questa categoria sembra in un primo momento semplice: si usa la serie -st- per la prossimità e la serie -1- per la lontananza.

La distanza della verbalizzazione precedente tuttavia può essere anche soggettiva. Questa "soggettività" può manifestarsi o con l'implicazione dell" "io", o mediante una connotazione peggiorativa, o tramite i semi /-realtà/, /- concreto/. Soltanto l'implicazione dell' "io" comprende anche le dimensioni di prossimità e di lontananza, realizzate sempre rispettivamente con la serie -st- e con la serie -1-. L'espressione della connotazione peggiorativa e dell'elemento d'irrealtà avviene esclusivamente con la serie -l-.

Quando i due criteri, distanza oggettiva e distanza soggettiva, si sovrappongono nei testi, abbiamo alcune regole di funzionamento che bisogna conoscere. Nel caso di attualizzazione d'un elemento subordinato alla distanza soggettiva cioè, la realizzazione nella pratica può farsi con le forme caratteristiche di tale distanza.

Se nello specchietto seguente si intende con 1 la distanza oggettiva di prossimità, con 2 la distanza oggettiva di lontananza, con $3 a$ la distanza soggettiva dell'implicazione personale e con $3 \mathrm{~b}$ la distanza soggettiva della connotazione peggiorativa e dell'irreale otteniamo le seguenti formule: $1+3 \mathrm{a}=-\mathrm{st}-$

$$
\begin{aligned}
& 1+3 b=-1- \\
& 2+3 a=-s t- \\
& 2+3 b=-1-
\end{aligned}
$$

La realizzazione linguistica della presupposizione di conoscenza si fa sempre usando la serie -1-.

L'identificazione del non noto con l'aiuto degli aggettivi dimostrativi avviene mediante la presentazione. Se si tratta di una presentazione "in praesentia" la scelta della serie dipende di nuovo dagli elementi prossimità e lontananza. In queste categorie a prima vista più semplici occorre tuttavia tenere anche conto di una gerarchia. 


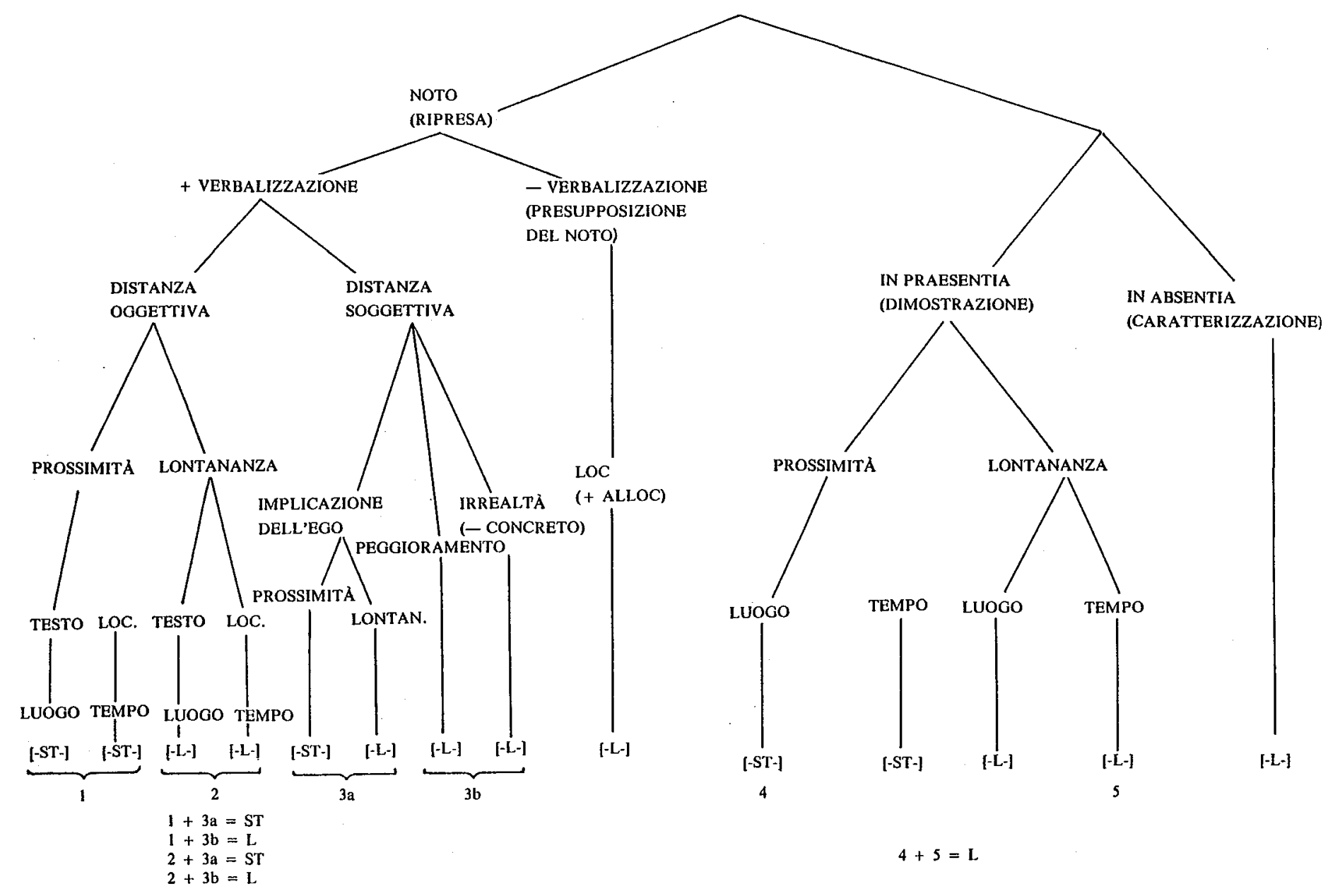


Il tempo predomina infatti sul luogo. Se c'è prossimità locale e lontananza temporale bisogna usare la realizzazione specifica per il tempo, ciò diventa esplicito nella formula: $4+5=-1-$.

\author{
ABBREVAZIONI DELLA LETTERATURA USATA PER IL CORPUS \\ (B.) Bărbulescu, M., Copii paradisului, Bucarest, Cartea Românească, 1985. \\ (E. L.) Lumnezianu, E., Fluxul apei dulci, Cluj-Napoca, Dacia, 1985. \\ (G. B.) Bălăiţă, G., Lumea în doua zile, Bucarest, Eminescu, 1985. \\ (M.) Modorcea, G., Rudele, Bucarest, Eminescu, 1985. \\ (O. I.) Ioaniţoaia, O., Nimeni nu are nimic de ascuns, Bucarest, Eminescu, 1985. \\ (S.) Simenon, G., (traduzione T. Cristea), Chinele galben, Bucarest, 1965. \\ (Z.) Zanc, G., Careul de fuga, Cluj-Napoca, Dacia, 1985.
}

\title{
Rezumat \\ PRAGMATICA ADJECTIVELOR DEMONSTATIVE ÎN LIMBA ROMÂNĂ
}

Analiza textuală a funcților adjectivelor demostrative din limba româna permite dinstingerea mai multor categorii semantico-pragmatice. La prima vedere demonstrativele servesc să identifice notiuni cunoscute şi / sau necunoscute. Noțiunile pot fi identificate printr-o verbalizare precedentă sau pot fi presupuse cunoscute. In primul caz verbalizarea care precedă se poate găsi la o distantă obiectiva sau subiectivă de vorbitor. Dacă distanta e obiectivă, e vorba fie de distanța din text, deci de o distanta spatială, fie de distanță în timp, absolută sau relativă. Cu alte cuvinte distanța în timp dintre evenimentul în care e implicata notiunea în cauza și povestirea vorbitorului.

Anafora de acest tip se realizează prin seria -st- pentru proximitate si prin seria -l- pentru depărtare. Trebuie să se țină seama însa că "distanța" poate fi şi subiectiva, și anume prin implicarea "eu-lui-“, prin conotarea peiorativa sau prin semele /- realitate/, /- concret/. Numai primul tip de subiectivitate contine dimensiunile apropiere si depărtare, realizate respectiv prin seriile -st- şi -1-. Conotarea peiorativa şi elementul irealitate se exprimă numai prin seria -1 - .

Cînd distanta obiectivă şi subiectivă se suprapun in text, limba recurge la anumite reguli care trebuie cunoscute. De exemplu realizarea lingvistică a presupoziției cunoaşterii noţiunii reluate se face întotdeauna cu seria -1-.

Identificarea unui element necunoscut prin demonstrative, catafora, se realizează prin prezentare. Dacă e vorba de o prezentare "in praesentia" alegerea seriei depinde din nou de elementele apropierere sau depărtare. Dar și in aceste cazuri trebuie să se țină seama de o anumita ierarhie. De exemplu timpul predomină asupra locului.

Rămîne de văzut dacă regulele stabilite de autoare în acest articol sînt valabile şi pentru celealte limbi romanice care dispun de un sistem binar. 